\title{
Pyroclastic Activity at Home Plate in Gusev Crater, Mars
}

\author{
S.W. Squyres ${ }^{1}$, O. Aharonson ${ }^{2}$, B.C. Clark $^{3}$, B. Cohen $^{4}$, L. Crumpler ${ }^{5}$, P.A. de Souza ${ }^{6}$, \\ W.H. Farrand ${ }^{7}$, R. Gellert ${ }^{8}$, J. Grant ${ }^{9}$, J.P. Grotzinger ${ }^{2}$, A.F.C. Haldemann ${ }^{10}$, J.R. \\ Johnson $^{11}$, G. Klingelhöfer ${ }^{12}$, K.W. Lewis ${ }^{2}$, R. Li ${ }^{13}$, T. McCoy ${ }^{14}$, A.S. McEwen ${ }^{15}$, H.Y. \\ McSween $^{16}$, D.W. Ming ${ }^{17}$, J.M. Moore ${ }^{18}$, R.V. Morris ${ }^{17}$, T.J. Parker ${ }^{10}$, J.W. Rice, Jr. ${ }^{19}$, S. \\ Ruff $^{19}$, M. Schmidt ${ }^{14}$, C. Schröder ${ }^{12}$, L.A. Soderblom ${ }^{11}$, A. Yen ${ }^{10}$ \\ ${ }^{1}$ Department of Astronomy, Space Sciences Building, Cornell University, Ithaca, NY 14853, USA \\ ${ }^{2}$ Division of Geological and Planetary Sciences, Caltech, Pasadena, CA 91125, USA \\ ${ }^{3}$ Lockheed Martin Corporation, Littleton, CO 80127, USA \\ ${ }^{4}$ Department of Earth and Planetary Sciences, University of New Mexico, Albuquerque, NM 87131, USA \\ ${ }^{5}$ New Mexico Museum of Natural History and Science, Albuquerque, NM 87104, USA \\ ${ }^{6}$ Pontifícia Universidade Católica do Rio de Janeiro, RJ, Brazil \\ ${ }^{7}$ Space Science Institute, Boulder, CO 80301, USA \\ ${ }^{8}$ Department of Physics, University of Guelph, Guelph, ON, N1G 2W1, Canada \\ ${ }^{9}$ Center for Earth and Planetary Studies, Smithsonian Institution, Washington, DC 20560, USA \\ ${ }^{10}$ Jet Propulsion Laboratory, California Institute of Technology, Pasadena, CA 91109, USA \\ ${ }^{11}$ United States Geological Survey, Flagstaff, AZ 86001, USA \\ ${ }^{12}$ Institut für Anorganische und Analytische Chemie, Johannes Gutenberg-Universität, Mainz, Germany \\ ${ }^{13}$ Department of Civil and Environmental Engineering and Geodetic Science, Ohio State University, \\ Columbus, OH 43210, USA \\ ${ }^{14}$ Department of Mineral Sciences, National Museum of Natural History, Smithsonian Institution, \\ Washington, DC 20560, USA \\ ${ }^{15}$ Lunar and Planetary Laboratory, University of Arizona, Tucson, AZ 85721, USA \\ ${ }^{16}$ Department of Earth and Planetary Sciences, University of Tennessee, Knoxville, TN 37996, USA \\ ${ }^{17}$ ARES, NASA Johnson Space Center, Houston, TX 77058, USA \\ ${ }^{18}$ NASA Ames Research Center, Moffett Field, CA, 94035, USA \\ ${ }^{19}$ Department of Geological Sciences, Arizona State University, Tempe, AZ 85287, USA
}




\begin{abstract}
Home Plate is a layered plateau in Gusev crater on Mars. It is composed of clastic rocks of moderately altered alkali basalt composition, enriched in some highly volatile elements. A coarse-grained lower unit is overlain by a finer-grained upper unit. Textural observations indicate that the lower strata were emplaced in an explosive event, and geochemical considerations favor an explosive volcanic origin over an impact origin. The lower unit likely represents accumulation of pyroclastic materials, while the upper unit may represent eolian reworking of the same pyroclastic materials.
\end{abstract}


Home Plate is a light-toned plateau $~ 90 \mathrm{~m}$ in diameter and 2-3 $\mathrm{m}$ high within the Inner Basin of the Columbia Hills, at Spirit's landing site in Gusev crater $(1,2,3)$. Home Plate appears prominent from orbit, and was identified after landing as a high priority target. It is the most extensive exposure of layered bedrock encountered by Spirit at Gusev to date.

Spirit arrived at the northern edge of Home Plate on Sol 744 (4), following the path shown in Figure 1. Images of the plateau show a thick stack of layered rocks, with a lower coarse-grained unit and an upper finer-grained unit (Figure 2). The lower unit is characterized by prominent parallel layering with low apparent dips, and a coarse granular texture (Figure 2b). Individual granules are roughly equant, and typically 0.5 to $3 \mathrm{~mm}$ in size. It is difficult to determine in Microscopic Imager (MI) images whether the granules are original clasts, such as accretionary lapilli, or textures reflecting postdepositional cementation (Figure S1). Toward the top of the lower unit is a massive section roughly $10 \mathrm{~cm}$ thick where layering becomes indistinct (Figure 3) and grains are difficult to identify in MI images (Figure S2).

A particularly striking feature in the lower unit is a $\sim 4-\mathrm{cm}$ clast with deformed layers beneath it, interpreted to be a bomb sag (Figure 3). Bomb sags are found in volcaniclastic deposits on Earth, where outsized clasts ejected from an explosive vent are emplaced ballistically into deformable materials, causing downward deflection of layering.

In contrast to the lower unit, the upper unit is fine grained, well sorted, finely laminated, and exhibits cross-stratification. On the northern edge of Home Plate, the upper unit 
exposes a facies that is well-bedded, and characterized by ubiquitous fine lamination that is arranged in bed sets with planar to low-angle cross-stratification (Figure 2c). Other features of this facies include gently dipping, curved or irregular surfaces of erosion, small-scale cut-and-fill structures, convex-upward laminations, and occasional intercalation of thin beds of high-angle cross-bedding. In MI images, this facies exhibits a distinctly clastic texture, with grains $200-400 \mu \mathrm{m}$ in diameter that are exceptionally well rounded and sorted (Figure S3).

A second facies in the upper unit that is particularly well developed at the eastern edge of Home Plate exhibits high-angle cross-bedding (Figure 4). Here, the geometry is expressed as wedge sets up to several tens of cm thick of distinctly trough-shaped crossstrata. Internal stratification ranges from finely laminated to more thickly laminated. Cross-strata also preserve evidence of reactivation surfaces, cut at variable angles and generally backfilled by cross-strata concordant with the scour surface. Such geometries typically form during reconfiguration of the bed in response to scouring during flow bursting, migration of three-dimensional bedforms with frontal scour pits, and at times when the sediment concentration of a flow is decreased.

We have used planar fits to bedding seen in Pancam images to estimate the structural attitudes of beds in the upper unit of Home Plate, at four locations that sample roughly a third of the plateau's perimeter (Figure S4). At all four locations the beds dip inward toward the center of Home Plate. The $1-\sigma$ range of derived dips is 5 to $20^{\circ}$, with occasional values up to $30^{\circ}$. Dips are consistent within each outcrop, suggesting that the 
measurements reflect a true structural trend and are not greatly influenced by low-angle cross-bedding.

Chemical compositions analyzed by the Alpha Particle X-ray Spectrometer (APXS) are given in Table 1. The outcrops Posey and Cool Papa Bell (5) from the upper unit were brushed with the Rock Abrasion Tool (RAT) prior to analysis. Barnhill, from the lower unit, could not be brushed; Pancam color images were used to select relatively dust-free regions. Fuzzy Smith, a small $(\sim 10 \mathrm{~cm})$ loose rock on the plateau, also could not be brushed. The lack of strong $\mathrm{SO}_{3}$ and $\mathrm{Cl}$ enrichments for unbrushed surfaces relative to brushed ones suggests that surface dust contamination was modest.

Most Home Plate outcrop rocks are fairly uniform in elemental composition, except for Barnhill Fastball, which has lower $\mathrm{Al}_{2} \mathrm{O}_{3}$ and $\mathrm{Na}_{2} \mathrm{O}$ and higher MgO. They are most similar to Masada, a scoriaceous float rock in the Inner Basin, and Irvine (6), a basaltic rock at the summit of Husband Hill. Home Plate outcrop rocks have a basaltic composition, with high alkali contents similar to some other basalts in Gusev crater (6). However, they have markedly higher abundances of some volatile minor/trace elements (Cl, Br, Zn, Ge).

Multispectral imaging of Home Plate outcrop rocks shows that clean surfaces have low albedo, and exhibit $~ 930 \mathrm{~nm}$ band absorptions consistent with the presence of lowcalcium pyroxene or possibly ferric oxyhydroxides (Figure S5). Such absorptions are similar to those observed in Clovis Class rocks on the west spur of Husband Hill (7). 
Mini-TES infrared spectra of dark-toned outcrops at Home Plate (Figure S6) indicate a strong component ( $\sim 45 \%)$ that resembles basaltic glass, similar to the spectra of Clovis Class rocks (8). In addition, deconvolution using a spectral library yields a best fit with $\sim 30 \%$ pigeonite (a clinopyroxene), 5\% olivine, and 10\% plagioclase. A small amount of sulfate $(\sim 10 \%)$ is also suggested. The surfaces that give Home Plate its light tone when viewed from orbit display the same spectrum of surface dust observed on other dustcovered rocks in Gusev crater (9).

Mössbauer Spectrometer (MB) mineralogy for Home Plate outcrop rocks is given in Table S1. Barnhill, Posey, and Cool Papa Bell are similar to one another. Of the total Fe present (Table 1), $16-18 \%$ resides in olivine, $22-24 \%$ in pyroxene, $27-29 \%$ in nanophase oxide, and 26-32\% in magnetite. These are among the most magnetite-rich rocks at Gusev crater (10). The ratio of $\mathrm{Fe}^{3+}$ to total iron $\left(\mathrm{Fe}^{3+/} \mathrm{Fe}_{\text {Total }}\right)$ is $\sim 0.52$.

Chemical analyses have been recast into mineralogy by calculating norms (Table 1), using MB determinations of $\mathrm{Fe}^{3+/} \mathrm{Fe}_{\text {Total }}$. The differences between the calculated mineralogy and the actual mineralogy determined by Mini-TES and MB indicate that Home Plate outcrop rocks did not form via equilibrium crystallization from anhydrous silicate liquids, as a norm calculation assumes.

Both MB and Mini-TES detect olivine and pyroxene, although abundances cannot be compared directly due to uncertainties in the Fe content of both phases. Mini-TES deconvolution yields $\sim 45 \%$ basaltic glass and no magnetite while MB yields abundant Fe from magnetite (26-32\%) and npOx (27-29\%). This apparent difference suggests that the 
npOx for these rocks may be spectrally similar to the Mini-TES glass component. Nondetection of magnetite by Mini-TES is expected; the instrument's detection limit for magnetite is high because some magnetite spectral features are longward of its bandpass and others are obscured by the atmospheric $\mathrm{CO}_{2}$ band at $15 \mu \mathrm{m}$.

Loose rocks atop Home Plate include the small, irregularly-shaped rock Fuzzy Smith (Figure S7). Its chemical composition is unlike any other rock investigated by either rover, with high Zn, the highest $\mathrm{Si}, \mathrm{K}$, and Ge measured at Gusev crater, and very low Ca and Fe (Table 1). No Mini-TES data were acquired for Fuzzy Smith. Mössbauer data reveal unique Fe mineralogy, with most of the Fe (64\%) in a phase we refer to as Fe?D1 that has not been detected in any other martian rock (Table S1). The Mössbauer parameters of Fe?D1 (isomer shift $\delta=0.28 \pm 0.02 \mathrm{~mm} / \mathrm{s}$ and quadrupole splitting $\Delta \mathrm{E}_{\mathrm{Q}}=$ $0.67 \pm 0.02 \mathrm{~mm} / \mathrm{s})$ are consistent with a Fe sulfide like pyrite and/or marcasite $\left(\mathrm{Fe}^{2+} \mathrm{S}_{2}\right.$ polymorphs) or with tetrahedrally coordinated $\mathrm{Fe}^{3+}$ in some phase (11). If the APXS and MB analyzed exactly the same material, then molar S/Fe does not favor the sulfide interpretation. Some phyllosilicates have tet-Fe ${ }^{3+}$ doublets with similar parameters, but the contribution of the subspectrum to the total MB spectrum (unlike what is observed in Fuzzy Smith) is $<50 \%$. Without additional chemical and mineralogical information (e.g., detection of sulfide or phyllosilicate by Mini-TES), we are not able to assign a mineralogical composition or a oxidation state to the Fe?D1 doublet.

Acid-sulfate leaching of basalt by volcanic vapors can produce amorphous, $\mathrm{SiO}_{2}$-rich residues (12), and such a process may have been involved in the formation of Fuzzy 
Smith. While Fuzzy Smith is highly quartz-normative, the calculated mineralogy is unlikely to be representative of a leached rock.

Several characteristics of Home Plate implicate an explosive process in its origin. These include the bomb sag, rounded granules in the lower unit that might be accretionary lapilli, and an infrared spectral signature suggesting basaltic glass. A coarse-grained lower unit that grades upward into finer materials is also consistent with an explosive origin. Both a volcanic explosion and an impact are candidate formative events.

Compositional evidence favors a volcanic origin. Home Plate outcrops are similar in chemistry and mineralogy to vesicular alkali-rich basalts that are abundant in the Inner Basin. This relationship suggests a common magmatic source and a volcanic origin for Home Plate, although clearly the style of emplacement is different.

An unusual aspect of Home Plate rocks is fractionation of $\mathrm{Cl}$ (and in some cases $\mathrm{Br}$ ) from S. Chlorine does not show correlations with incompatible elements like K that could point to igneous fractionation as its source, nor with $\mathrm{Al}$ that might point to weathering or aqueous alteration. Instead, the $\mathrm{Cl}$ enrichment might be explained as interaction of magma with a brine. Alternatively, the enrichment in $\mathrm{Cl}$ but not in $\mathrm{S}$ could reflect degassing in an oxidized basaltic magma, causing $\mathrm{S}$ to partition preferentially into the vapor phase (13) and decreasing the $\mathrm{S} / \mathrm{Cl}$ and $\mathrm{S} / \mathrm{Br}$ ratios. In either case, a volcanic origin would be implied. However, we cannot rule out the possibility that the Cl enrichment is present in a surface coating that is resistant to RAT brushing, rather than in the bulk rock. 
Home Plate is also strongly enriched in the volatile elements Ge and Zn. While Ge tends to be high in meteoritic material, the lack of a corresponding Ni enrichment suggests that the Ge in Home Plate is not primarily of meteoritic origin. Instead, the enrichment in these volatile elements may reflect condensation of volcanic vapor. Germanium is also well known for enrichment in sulfides and zinc mineralizations, especially under hydrothermal conditions (14). Again, a volcanic origin for Home Plate is implied by either interpretation.

Taken together, our observations suggest that Home Plate is composed of debris deposited from a hydrovolcanic explosion that occurred when alkali-rich basaltic magma came into contact with subsurface fluid, perhaps brine. Both the bomb sag and the compositional similarity of Home Plate to basalts found nearby suggest that the deposits lie close to the source vent. Bomb sags on Earth typically indicate that the deformed materials were wet at the time of emplacement, but we cannot rule out the possibility of sag formation resulting from compaction and gas-supported flow of dry materials.

Some aspects of the cross stratification in the upper unit are consistent with deposition from a volcanic surge $(15,16)$. However, because they develop from highly turbulent flows, surge deposits close to the source vent are often coarsely stratified, and on average poorly sorted with a component of coarser grains including outsized bombs and blocks (17). These attributes are not observed in the upper unit. Furthermore, the cross-strata of surge deposits commonly exhibit deposition along the stoss side as well as the lee side of 
the bedforms; in contrast, the cross-strata preserved at Home Plate are dominated by stoss-side truncation (only one observed set shows stoss-side accretion) suggesting little deposition from fallout.

The upper unit at Home Plate shows persistently fine lamination, and very well sorted and rounded grains. These observations point toward a process like eolian transport that increased the textural maturity of the sediments, suggesting that the upper unit may have formed by eolian reworking of pyroclastic debris derived from the same source as the lower unit. The planar to low-angle stratification would have formed by the migration of impact ripples over a sand sheet surface, while the large scale cross stratification would have been produced by migration of dunes. This interpretation is consistent with the abrupt contact between lower unit facies with upper unit facies, and the lack of any evidence for depositional continuity.

Home Plate is a quasi-circular plateau with beds that dip toward its center. One plausible explanation for this geometry is that either a volcanic structure (e.g., a maar or tuff ring) or an impact crater provided bowl-shaped relief that was filled with pyroclastic materials. Because settling from suspension tends to produce layers that conform to and drape underlying topography, emplaced layers may have conformed to the depression's shape. Post-depositional compaction that induced subsidence in the deepest portions could have further rotated beds toward the center. Subsequent erosion may have stripped away both the original confining structure and pyroclastic materials that lay outside it, leaving behind a raised platform of layered materials that dip inward. Indeed, the Columbia Hills exhibit a paucity of small impact craters relative to the stratigraphically younger lava 
plains nearby, indicating that significant amounts (perhaps meters) of erosion have occurred (18). And while there is strong evidence that the rocks of Home Plate lie close to their source vent, we have not found evidence that Home Plate itself is the location of the vent. Indeed, a probable source vent has not yet been found along Spirit's traverse. If, as we suspect, Home Plate is a remnant of a formerly more extensive explosive volcanic deposit, then investigation of other nearby layered materials may reveal a genetic relationship to Home Plate.

Home Plate was identified prior to Spirit's landing as a high priority target, and its apparently layered character led to suggestions of lacustrine, eolian, or pyroclastic origin (19). Deposits of similar appearance are common on Mars. Our conclusions suggest that pyroclastic deposits may be common elsewhere, particularly in settings where magmas have come into contact with ground ice or water. 


\section{References and Notes}

1. S.W. Squyres et al., Science 305, 794, doi:10.1126/science.3050794 (2004).

2. H.Y. McSween et al., Science 305, 842, doi:10.1126/science.3050842 (2004).

3. R.E. Arvidson et al., J. Geophys. Res. 111, E02S01, doi:10.1029/2005JE002499 (2006).

4. A martian solar day has a mean period of 24 hours 39 minutes and 35.244 seconds, and is referred to as a "sol".

5. All of the rocks at Home Plate are named after players from the Negro Leagues of baseball that existed prior to the racial integration of Major League Baseball. The names are informal, and not approved by the International Astronomical Union.

6. H.Y. McSween et al., J. Geophys. Res. 111, E09S91, doi:10.1029/2006JE002698 (2006).

7. W.H. Farrand, J.F. Bell III, J.R. Johnson, S.W. Squyres, J. Soderblom, and D.W. Ming, J. Geophys. Res. 111, E02S15, doi:10.1029/2005JE002495 (2006).

8. S.W. Squyres et al., J. Geophys. Res. 111, E02S11, doi:10.1029/2005JE002562 (2006).

9. S.W. Ruff et al., J. Geophys. Res. 111, E12S18, doi:10.1029/2006JE002747 (2006).

10. R.V. Morris et al., J. Geophys. Res. 111, E02S13, doi :10.1029/2005JE002584 (2006).

11. R.G. Burns, in Remote Geochemical Analysis: Elemental and Mineralogical Composition, C. M. Pieters and P. A. J. Englert (eds.), pp. 539-556, Cambridge University Press, Cambridge (1993).

12. R.V. Morris et al., Lunar and Planetary Science XXXI, Abstract \#2014, March 13-17, 2000, the Lunar and Planetary Institute, Houston, TX (CD-ROM).

13. B. Scaillet, B. Clemente, B.W. Evans, and M. Pichavant, J. Geophys. Res. 103, B10, 23,937, doi:0.1029/98JB02301 (1998).

14. L.R. Bernstein, Geochim. Cosmochim. Acta 49, 2409 (1985).

15. R.V. Fisher and A.C. Waters, Amer. Jour. Sci. 268, p. 157 (1970).

16. K.H. Wohletz, and M.F. Sheridan, in C.E. Chapin and W.E. Elston (eds), Geol. Soc. Amer. Special Paper 180, 177 (1979)

17. D.M Rubin, Cross-bedding, bedforms, and paleocurrents. Society of Economic Paleontologists and Mineralogists, Tulsa, 187 pp. (1987).

18. J.A. Grant, S.A. Wilson, S.W. Ruff, M.P. Golombek, and D.L. Koestler, Geophys. Res. Lett. 33, L16202, doi:10.1029/2006GL026964 (2006).

19. N.A. Cabrol et al., J. Geophys. Res. 108, E12, 8076, doi:10.1029/2002JE002026 (2003).

20. This research was carried out for the Jet Propulsion Laboratory, California Institute of Technology, under a contract with the National Aeronautics and Space Administration. 


\section{Tables}

Table 1: APXS analyses and calculated normative mineralogy for Home Plate rocks. Analyses are in wt.\%, except $\mathrm{Ni}, \mathrm{Zn}, \mathrm{Br}$ and $\mathrm{Ge}$ in ppm. Sample homogeneity is assumed. Uncertainties represent 1- $\sigma$ errors in X-ray peak area. Rock names in bold were brushed using the RAT, those not bold were not brushed. Fe was partitioned between FeO and $\mathrm{Fe}_{2} \mathrm{O}_{3}$ using Mössbauer-determined $\mathrm{Fe}^{3+/} \mathrm{Fe}_{\text {Total }}$ ratios (see Table S1). For rocks where no Mössbauer data were obtained, all Fe is reported as FeO and norms were calculated using the average value for Home Plate outcrop rocks of $\mathrm{Fe}^{3+} / \mathrm{Fe}_{\text {Total }}=0.52$. Norms were calculated without $S$, because $S$ is assumed to be present as sulfate rather than sulfide.

\begin{tabular}{|c|c|c|c|c|c|c|}
\hline Oxide & $\begin{array}{c}\text { Barnhill } \\
\text { Ace }\end{array}$ & $\begin{array}{l}\text { Barnhill } \\
\text { Fastball }\end{array}$ & Posey & $\begin{array}{c}\text { Cool Papa } \\
\text { Bell } \\
\text { Stars } \\
\end{array}$ & $\begin{array}{c}\text { Cool Papa } \\
\text { Bell } \\
\text { Crawfords } \\
\end{array}$ & Fuzzy Smith \\
\hline $\mathrm{SiO}_{2}$ & $45.2 \pm 0.27$ & $45.3 \pm 0.29$ & $45.4 \pm 0.38$ & $46.0 \pm 0.29$ & $46.6 \pm 0.39$ & $68.4 \pm 0.62$ \\
\hline $\mathrm{TiO}_{2}$ & $0.74 \pm 0.06$ & $0.67 \pm 0.06$ & $1.01 \pm 0.06$ & $0.93 \pm 0.06$ & $1.11 \pm 0.07$ & $1.71 \pm 0.08$ \\
\hline $\mathrm{Al}_{2} \mathrm{O}_{3}$ & $8.91 \pm 0.08$ & $7.85 \pm 0.08$ & $9.31 \pm 0.10$ & $9.30 \pm 0.09$ & $9.98 \pm 0.12$ & $6.31 \pm 0.08$ \\
\hline $\mathrm{Fe}_{2} \mathrm{O}_{3}$ & $10.4 \pm 0.04$ & & $8.73 \pm 0.05$ & $9.77 \pm 0.04$ & & $4.84 \pm 0.04$ \\
\hline $\mathrm{Cr}_{2} \mathrm{O}_{3}$ & $0.45 \pm 0.03$ & $0.49 \pm 0.03$ & $0.32 \pm 0.03$ & $0.39 \pm 0.03$ & $0.34 \pm 0.03$ & $0.06 \pm 0.03$ \\
\hline $\mathrm{FeO}$ & $8.32 \pm 0.03$ & $17.8 \pm 0.07$ & $7.55 \pm 0.04$ & $8.11 \pm 0.03$ & $15.4 \pm 0.09$ & $2.45 \pm 0.02$ \\
\hline $\mathrm{MnO}$ & $0.39 \pm 0.01$ & $0.47 \pm 0.01$ & $0.32 \pm 0.01$ & $0.31 \pm 0.01$ & $0.29 \pm 0.01$ & $0.15 \pm 0.01$ \\
\hline $\mathrm{MgO}$ & $9.19 \pm 0.09$ & $12.0 \pm 0.11$ & $9.48 \pm 0.10$ & $9.59 \pm 0.09$ & $10.3 \pm 0.12$ & $4.16 \pm 0.08$ \\
\hline $\mathrm{CaO}$ & $6.07 \pm 0.04$ & $5.80 \pm 0.04$ & $6.65 \pm 0.04$ & $6.50 \pm 0.04$ & $6.74 \pm 0.05$ & $1.93 \pm 0.02$ \\
\hline $\mathrm{Na}_{2} \mathrm{O}$ & $3.10 \pm 0.17$ & $2.35 \pm 0.17$ & $3.50 \pm 0.19$ & $3.25 \pm 0.18$ & $3.36 \pm 0.21$ & $2.92 \pm 0.21$ \\
\hline $\mathrm{K}_{2} \mathrm{O}$ & $0.32 \pm 0.05$ & $0.23 \pm 0.05$ & $0.42 \pm 0.06$ & $0.21 \pm 0.05$ & $0.32 \pm 0.06$ & $2.76 \pm 0.07$ \\
\hline $\mathrm{P}_{2} \mathrm{O}_{5}$ & $0.87 \pm 0.07$ & $0.79 \pm 0.07$ & $1.37 \pm 0.07$ & $1.12 \pm 0.07$ & $1.27 \pm 0.08$ & $0.68 \pm 0.07$ \\
\hline $\mathrm{SO}_{3}$ & $5.67 \pm 0.06$ & $4.63 \pm 0.06$ & $4.81 \pm 0.06$ & $3.75 \pm 0.05$ & $2.91 \pm 0.05$ & $3.39 \pm 0.05$ \\
\hline $\mathrm{Cl}$ & $1.31 \pm 0.02$ & $1.57 \pm 0.02$ & $1.94 \pm 0.02$ & $1.74 \pm 0.02$ & $1.35 \pm 0.02$ & $0.63 \pm 0.01$ \\
\hline $\mathrm{Ni}$ & $317 \pm 35$ & $352 \pm 39$ & $379 \pm 35$ & $318 \pm 37$ & $297 \pm 40$ & $272 \pm 33$ \\
\hline $\mathrm{Zn}$ & $400 \pm 11$ & $415 \pm 14$ & $407 \pm 11$ & $422 \pm 13$ & $314 \pm 14$ & $679 \pm 14$ \\
\hline $\mathrm{Br}$ & $475 \pm 17$ & $370 \pm 18$ & $181 \pm 15$ & $203 \pm 16$ & $91 \pm 15$ & $21 \pm 13$ \\
\hline Ge & $70 \pm 15$ & $70 \pm 15$ & $30 \pm 10$ & $30 \pm 10$ & $30 \pm 10$ & $190 \pm 20$ \\
\hline \multicolumn{7}{|l|}{ Mineral } \\
\hline Quartz & 2.3 & 2.6 & & 1.9 & 0.5 & 35.3 \\
\hline Feldspars & 37.6 & 31.5 & 40.6 & 38.9 & 41.5 & 33.4 \\
\hline Orthoclase & 1.9 & 1.4 & 2.5 & 1.2 & 1.9 & 16.3 \\
\hline Albite & 26.2 & 19.9 & 29.6 & 27.5 & 28.4 & 17.1 \\
\hline Anorthite & 9.5 & 10.2 & 8.5 & 10.2 & 11.2 & \\
\hline Actinolite & & & & & & 6.7 \\
\hline Diopside & 11.9 & 10.7 & 12.4 & 11.7 & 11.0 & 4.0 \\
\hline Hypersthene & 23.0 & 31.3 & 22.6 & 23.8 & 25.2 & 8.5 \\
\hline Olivine & & & 0.3 & & & \\
\hline $\begin{array}{l}\text { Forsterite } \\
\text { Favalite }\end{array}$ & & & 0.3 & & & \\
\hline Magnetite & 15.1 & 14.9 & 12.7 & 14.2 & 12.7 & 3.3 \\
\hline Chromite & 0.7 & 0.7 & 0.5 & 0.6 & 0.5 & 0.1 \\
\hline Ilmenite & 1.4 & 1.3 & 1.9 & 1.8 & 3.3 & 3.3 \\
\hline Apatite & 2.1 & 1.9 & 3.2 & 2.7 & 3.0 & 1.6 \\
\hline Hematite & & & & & & 0.2 \\
\hline
\end{tabular}




\section{Figures}

Figure 1: Home Plate as viewed from orbit. North is at the top. The path followed by the rover is shown, and the locations of rocks discussed in the text are shown. HiRISE image PSP_001513_1655, acquired on Nov. 22, 2006. Image scale is $27.1 \mathrm{~cm} /$ pixel, mapprojected to $25 \mathrm{~cm} /$ pixel. The scene is illuminated from the west with an incidence angle of 60 degrees.

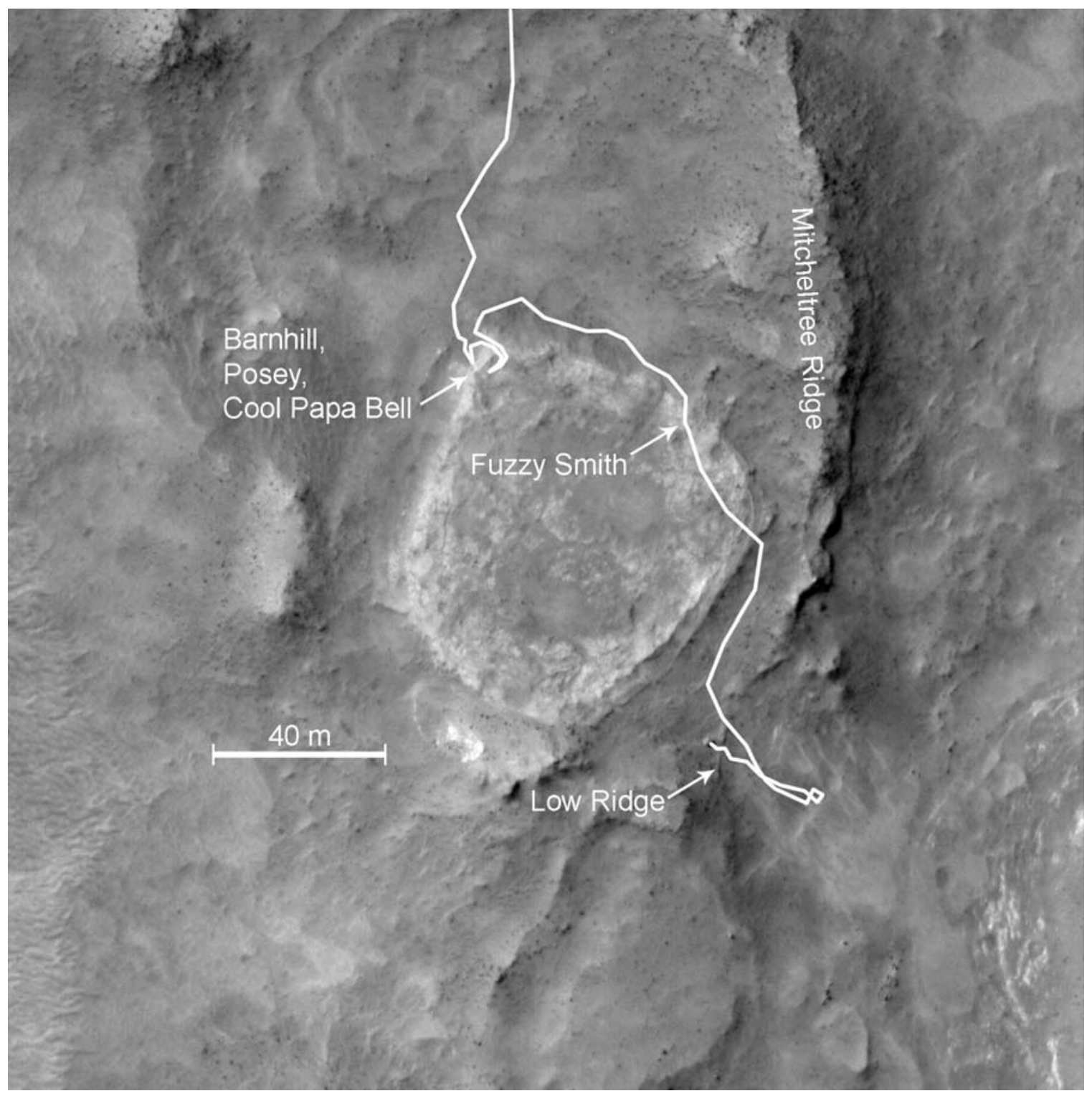


Figure 2: The northern edge of Home Plate (a), showing the coarse-grained lower unit (b) and the fine-grained upper unit (c). False color image obtained using Pancam's L2, L5, and L7 filters (753, 535, and $440 \mathrm{~nm}$, respectively) on Sols 748-751. Approximate scale across both (b) and (c) is $\sim 45 \mathrm{~cm}$. The apparent curvature of the horizon in (a) results from the high rover tilt when the image was acquired.

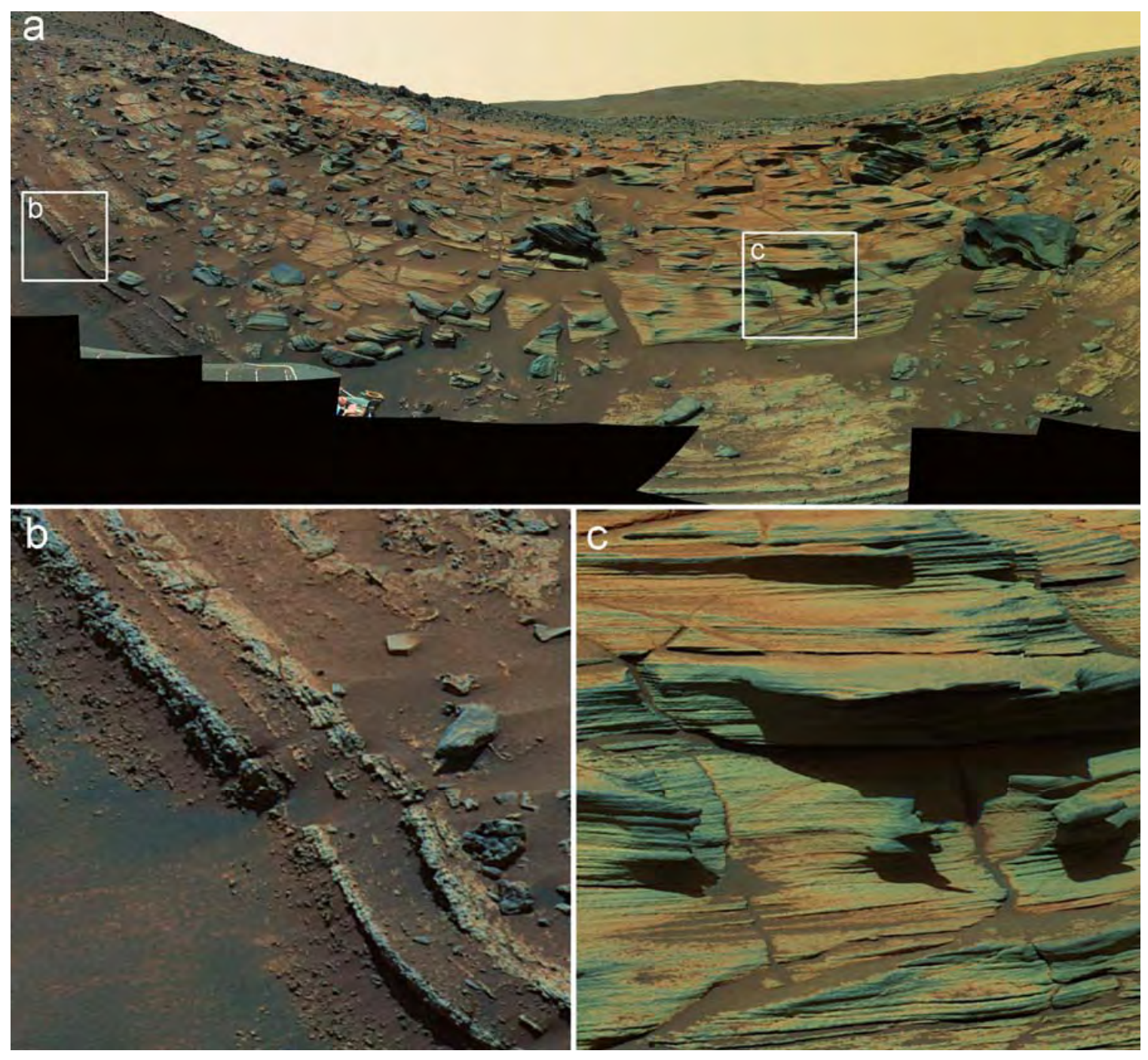


Figure 3: The lower coarse-grained unit, showing granular textures toward the bottom of the image and massive textures with rectilinear fracturing toward the top. Also shown is a feature that we interpret to be a bomb sag (arrow). The bomb is about $4 \mathrm{~cm}$ across. False color image obtained using Pancam's L2, L5, and L7 filters on Sol 751.

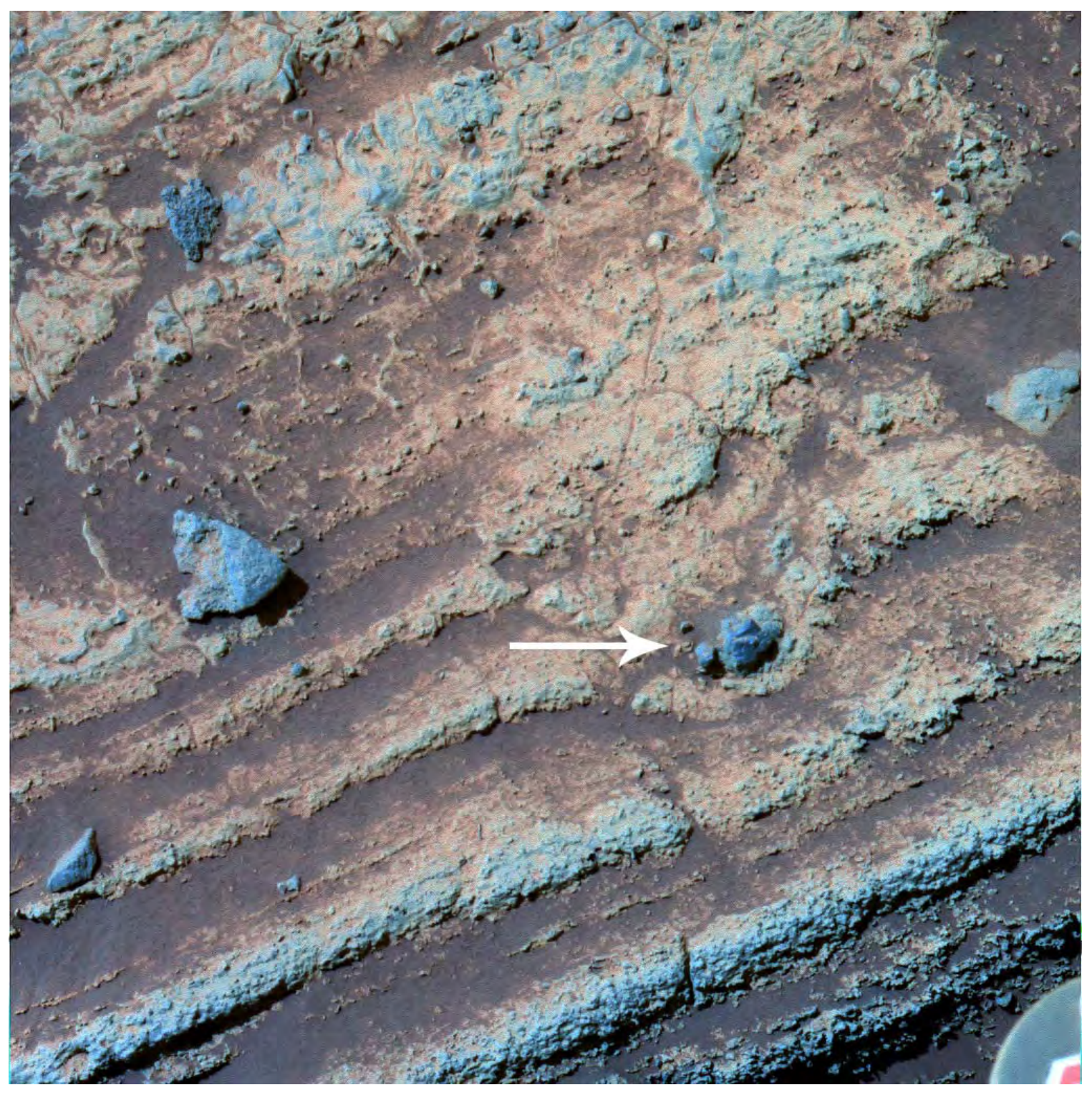


Figure 4: High-angle cross-bedded sandstone at the northeast edge of Home Plate. Scale across the image is $\sim 1.5-2 \mathrm{~m}$. Pancam image 2P195076279 acquired on Sol 774.

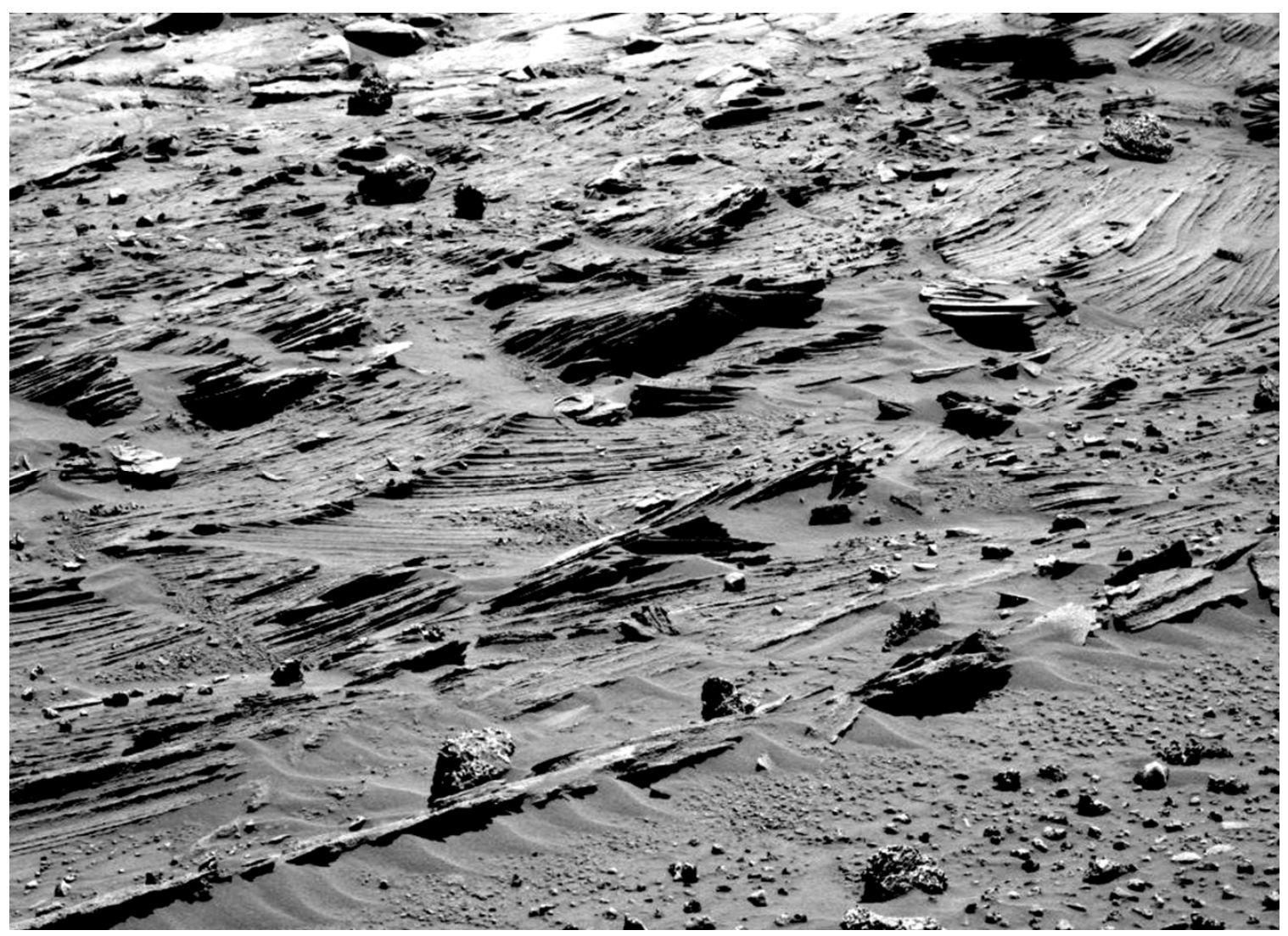




\section{Supplemental Online Material}

Figure S1: Microscopic Imager image of the lower unit of Home Plate, showing coarse granules. Scale across the image is $3 \mathrm{~cm}$. Microscopic Imager image 2M192958525.

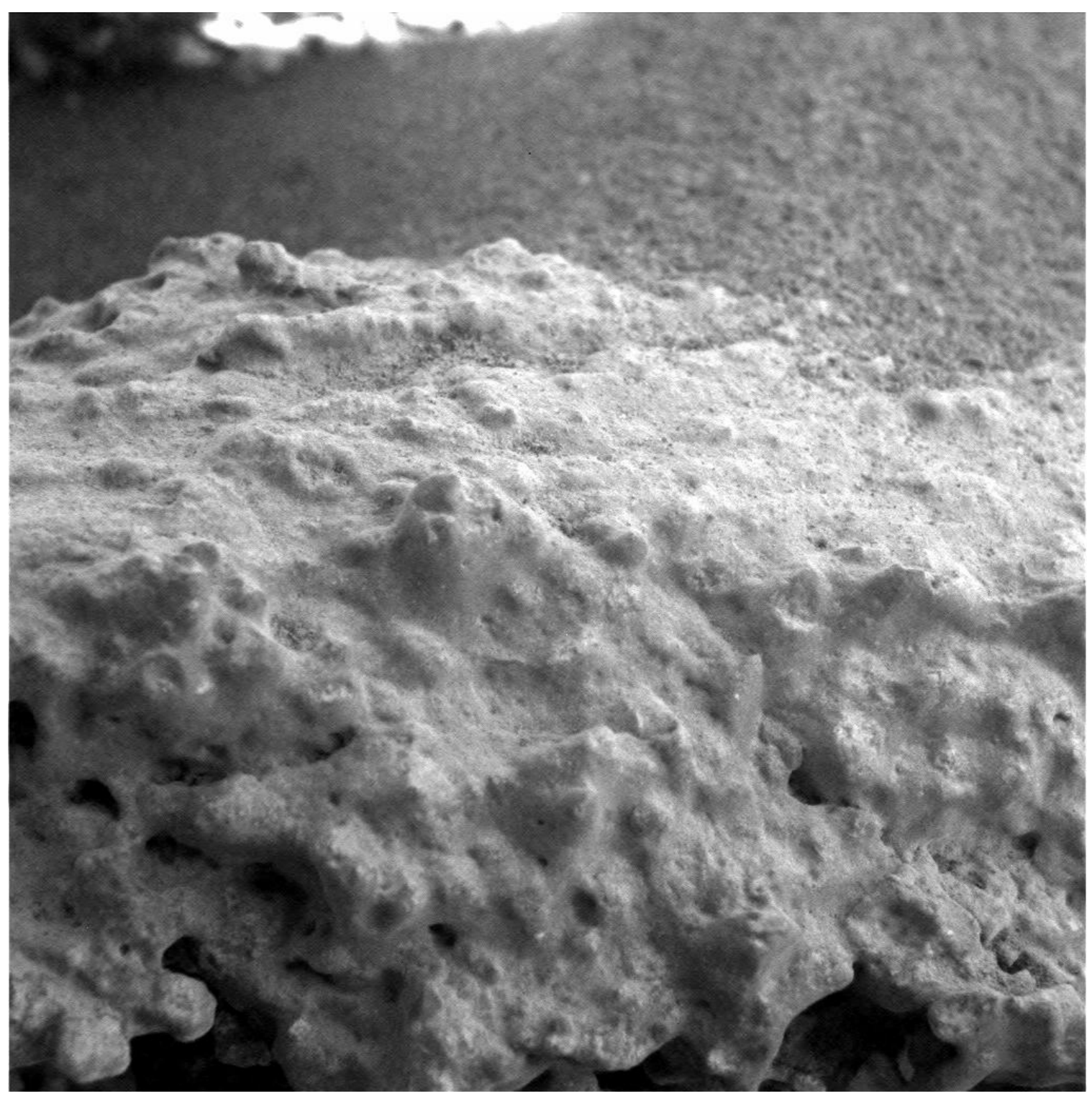


Figure S2: Microscopic Imager image of the lower unit of Home Plate, showing indistinct grain boundaries. Scale across the image is $3 \mathrm{~cm}$. Microscopic Imager image 2M192682040.

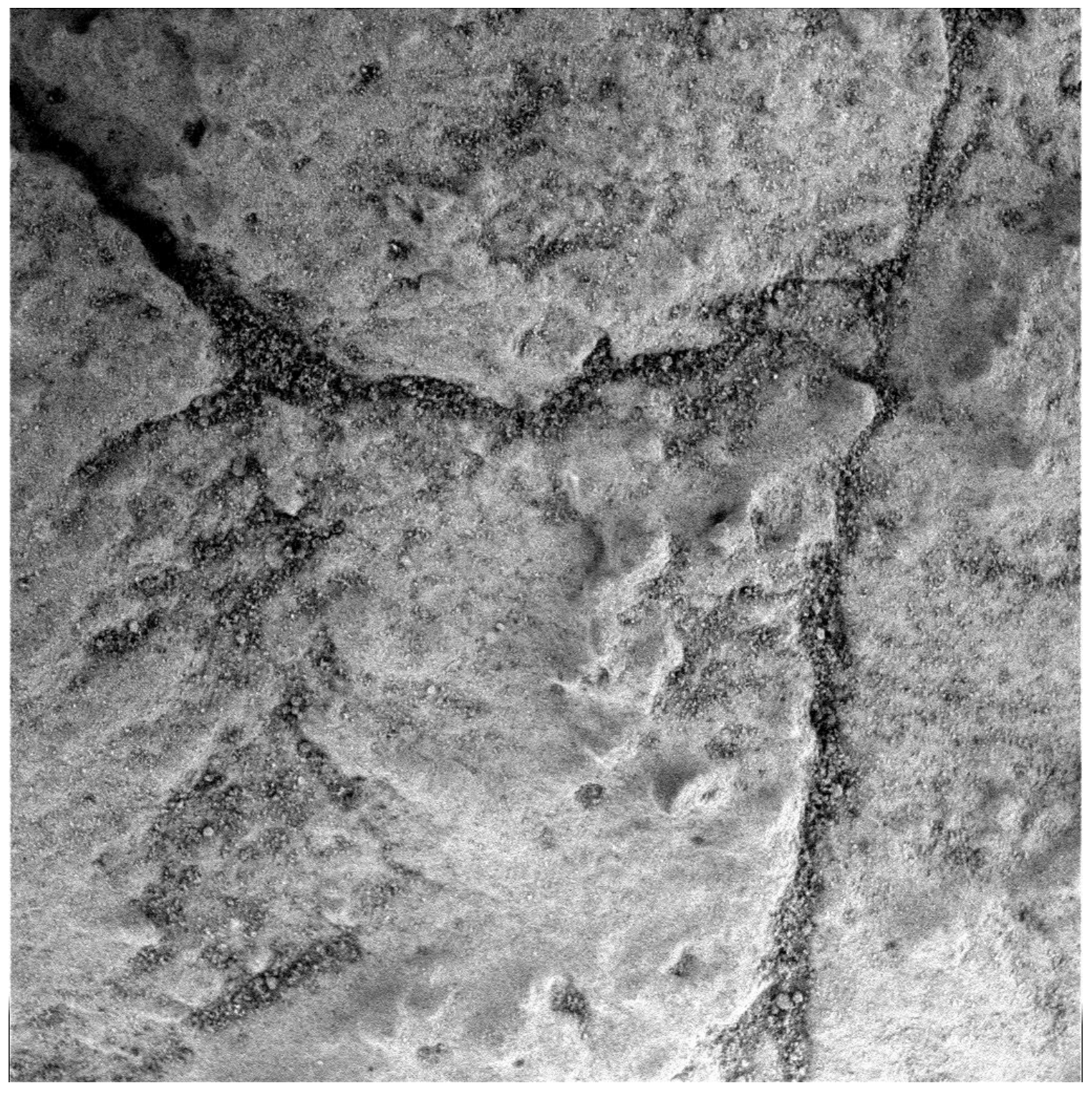


Figure S3: Microscopic Imager image of a portion of the upper unit of Home Plate that has been brushed using the Rock Abrasion Tool. Grains are very well rounded and sorted. Scale across the image is $3 \mathrm{~cm}$. Microscopic Imager image 2M194100679.

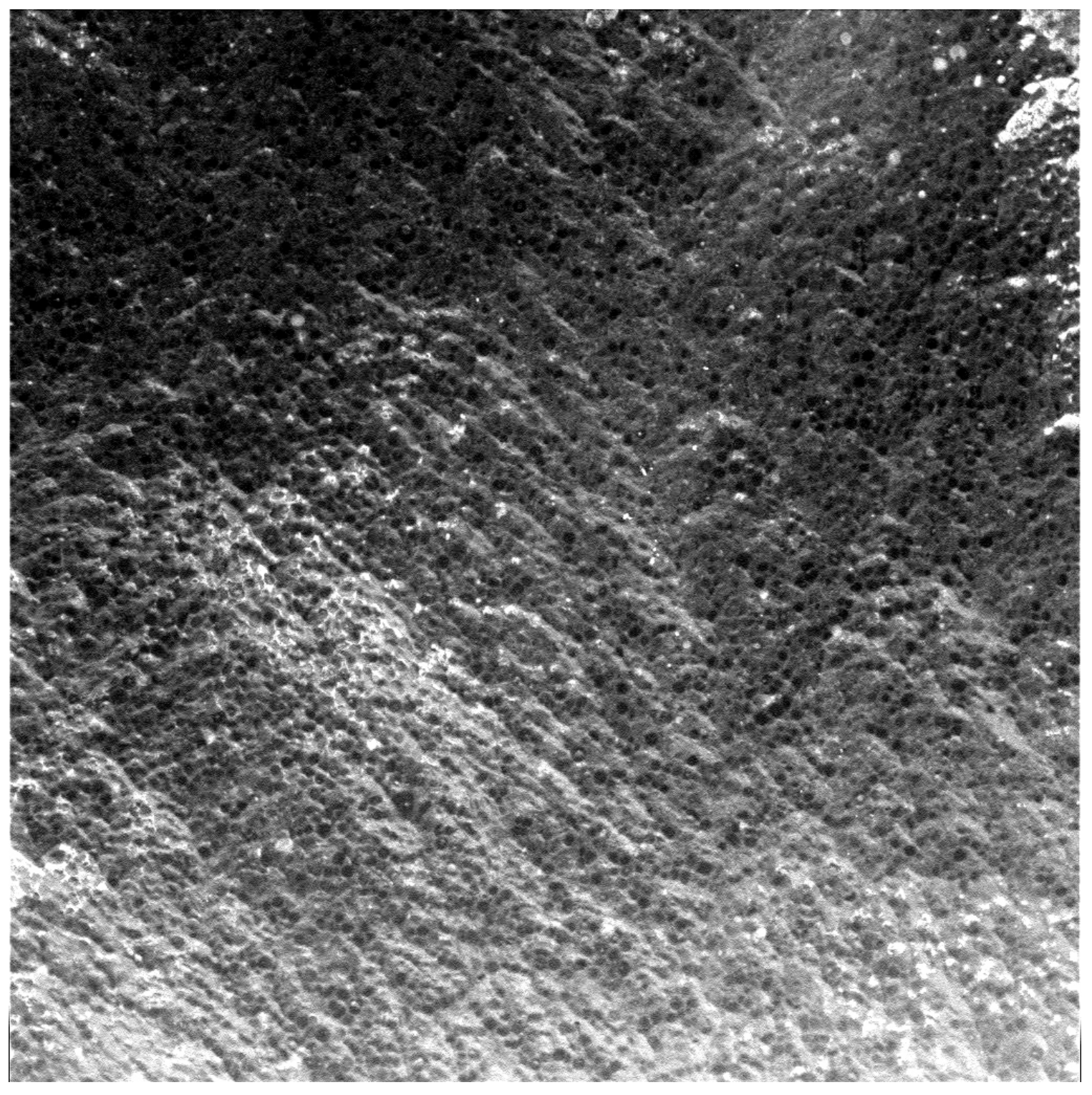


Figure S4: Bedding plane orientation at four locations imaged at Home Plate, shown on HiRISE image PSP_001513_1655. North is at the top. Spirit site and position numbers for each location are given; e.g., 124/55 denotes Site 124, Position 55. Histograms show measured strikes and dips at each location. A total of 93 measurements of strike and dip were made. Black arrows indicate the orientation of a plane describing the face of the outcrop. To determine strike and dip, parameters describing plane geometries were obtained from a principal component analysis applied to the coordinates of points along individual laminae identified in stereo images. Generally, layers were more than 75 pixels in extent (i.e. $10 \mathrm{~cm}$ at a maximum distance of $5 \mathrm{~m}$ ), and a similar number of data points were extracted from the topographic grids. Layers were only used where the distance to the target was small enough that the natural topography of the outcrop was clearly larger than the noise level, typically $<1 \mathrm{~cm}$. Measurements were rejected if coordinates were approximately collinear and hence failed to produce a unique planar solution, or in instances where the coordinates were not well fit by a plane.
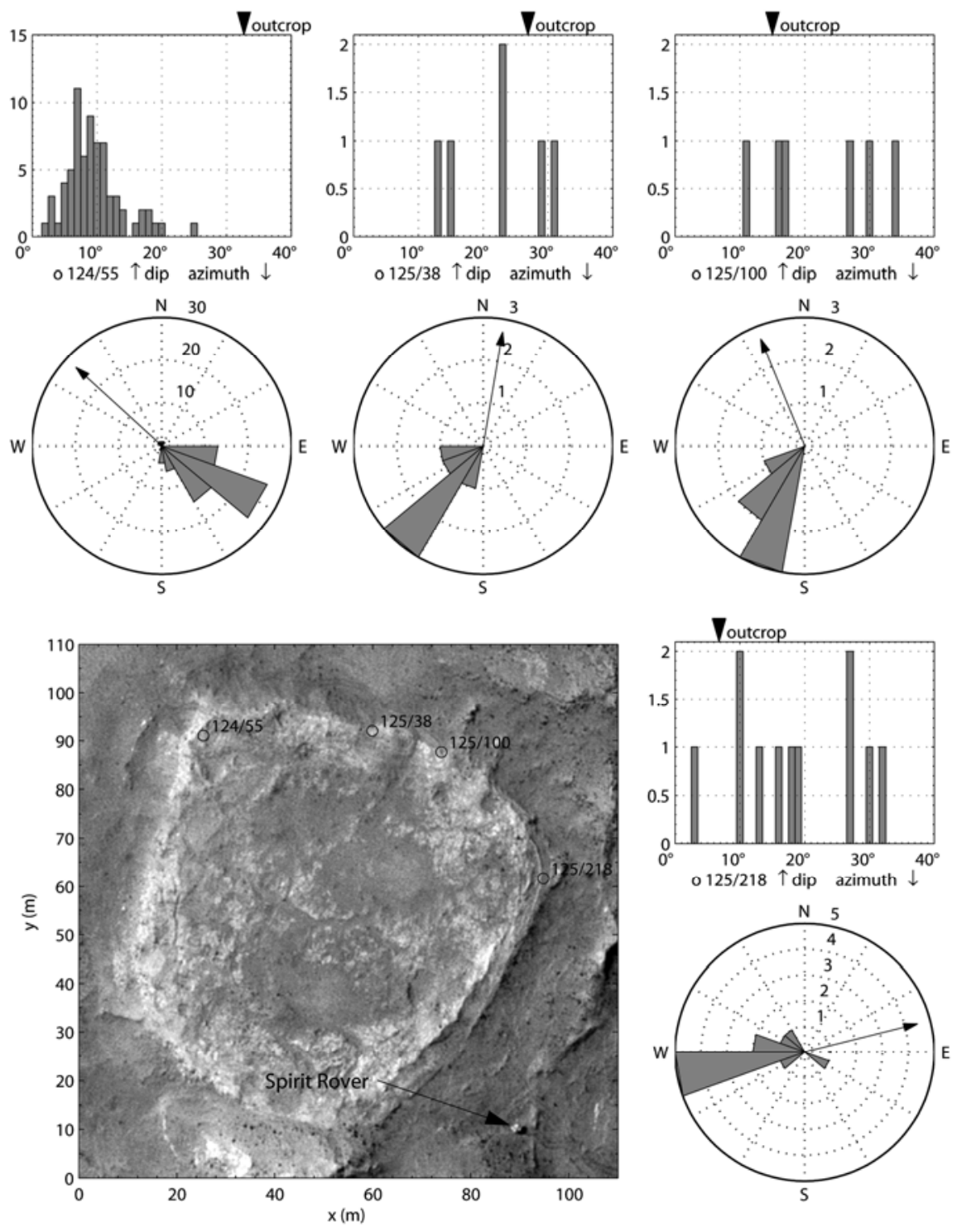
Figure S5: Pancam visible/near-IR spectra for the rocks Posey and Cool Papa Bell. R* is relative reflectance, defined as $\mathrm{I} / \mathrm{F}$ divided by the cosine of the incidence angle

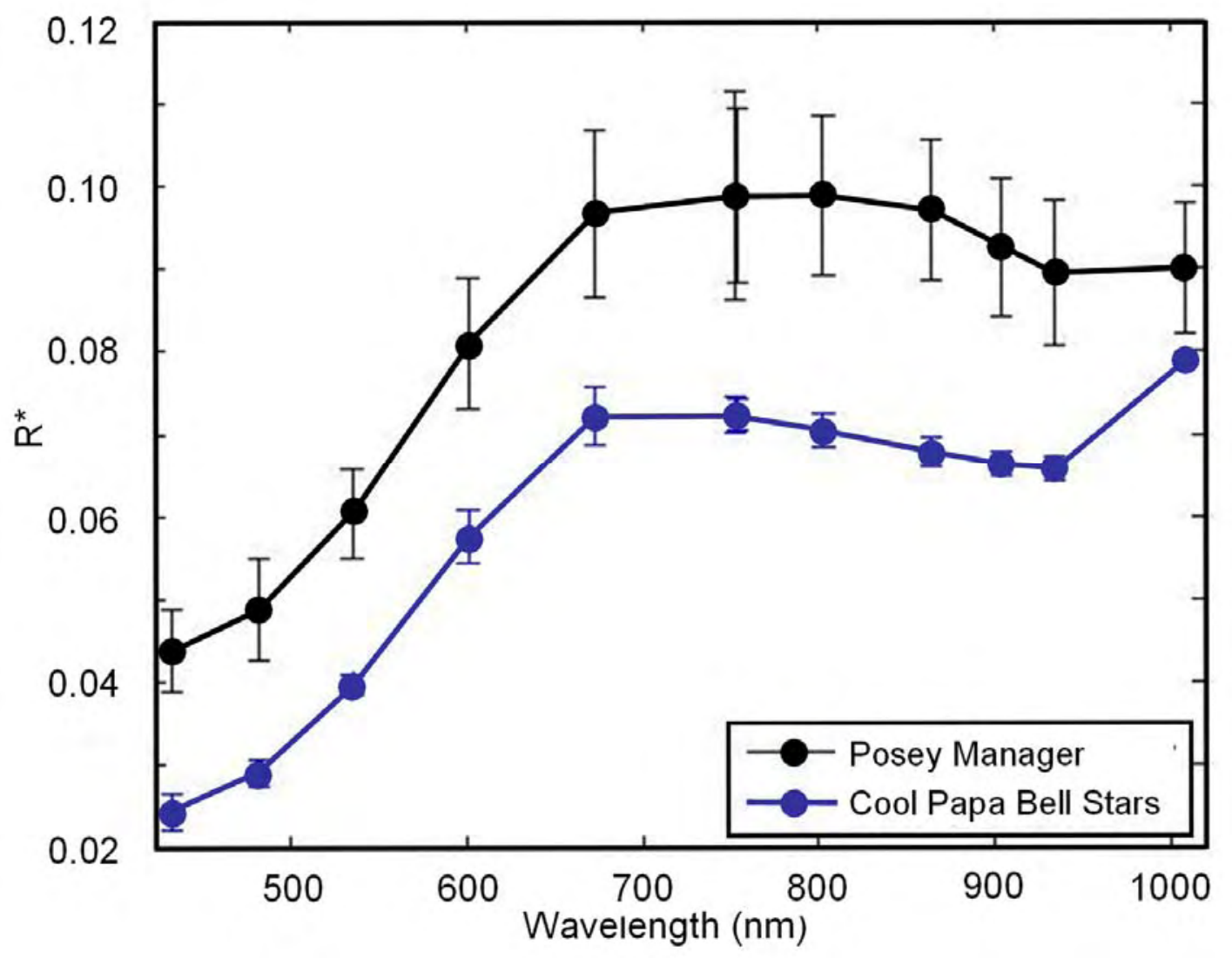


Figure S6: Mini-TES emissivity spectrum of average Home Plate rocks. Black curve shows the data, blue curve shows the spectrum of the mineralogical model fit to the data described in the text. The spectral region centered around $15 \mathrm{~m}$ is obscured by atmospheric $\mathrm{CO}_{2}$.

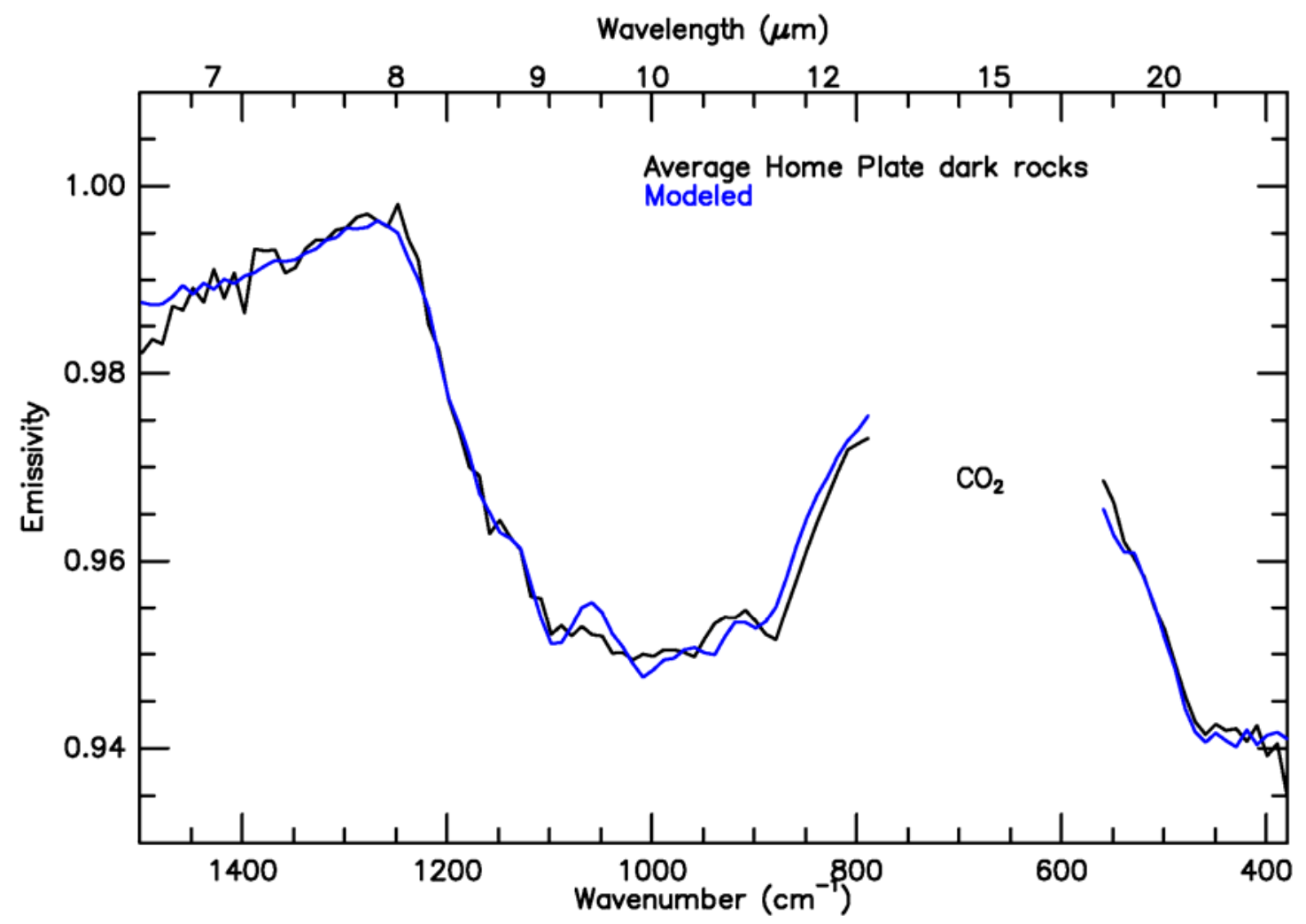


Figure S7: Approximate true color image of the rock Fuzzy Smith, assembled using data from all of Pancam's color filters. Approximate size of Fuzzy Smith is $\sim 10 \mathrm{~cm}$. Image sequence P2595 acquired on Sol 772.

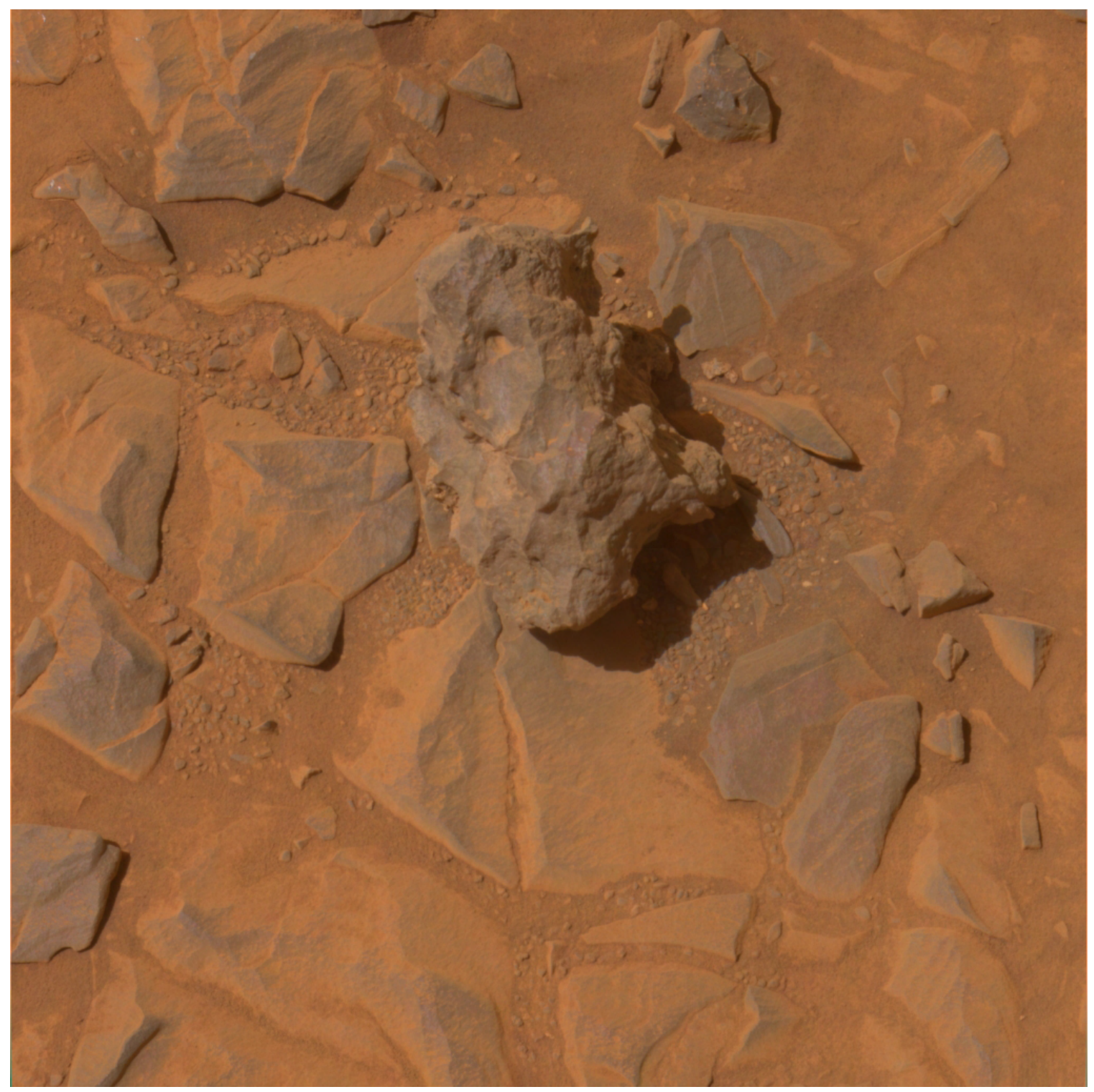




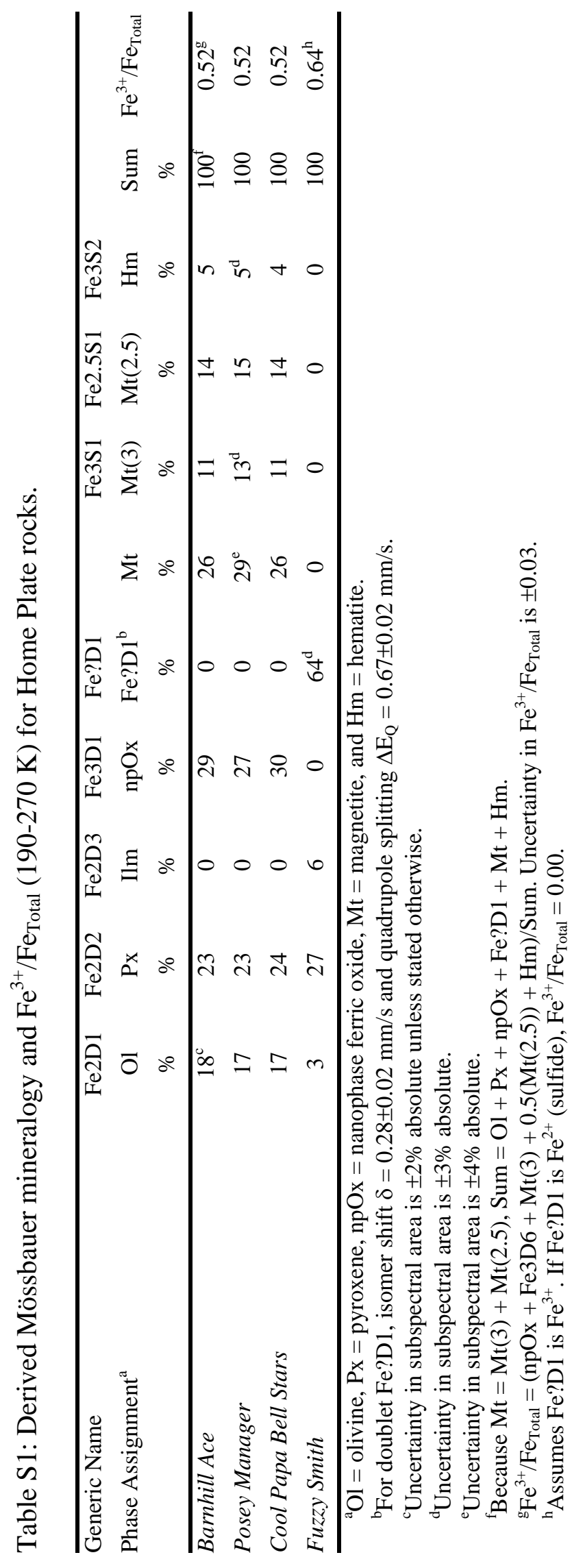

